\title{
O CONFLITO DE INTERESSES NA RECUPERAÇÃO JUDICIAL: PROBLEMAS, PROPOSTAS LEGISLATIVAS E CONTRIBUIÇÕES CRÍTICAS
}

\author{
Murilo Ramalho Procópio*
}

Resumo: O presente artigo se volta para o regime jurídico brasileiro de deliberação de credores no contexto da Recuperação Judicial de empresas, sobre o qual se concentra grande parte da produção teórica relacionada à regulação brasileira da empresa em crise. Neste sentido, pretende-se, com o presente trabalho, analisar segundo uma perspectiva crítica o regime das deliberações dos credores na recuperação judicial, abordando os diferentes entraves apontados pela doutrina, assim como as propostas legislativas que tentam regulamentar os problemas existentes.

Palavras-chave: recuperação judicial; conflito de interesses; deliberação; crise; teoria crítica.

\section{THE CONFLICT OF INTERESTS ON JUDICIAL RECOVERY: PROBLEMS, LEGISLATIVE PROPOSALS AND CRITICAL CONTRIBUTIONS}

\begin{abstract}
This article focuses on the Brazilian legal regime for the deliberation of creditors in the context of Judicial Recovery of companies, on which a large part of the theoretical production related to the Brazilian regulation of the company in crisis is concentrated. In this sense, it is intended, with the present work, to critically analyze the regime of the deliberations of creditors in the judicial recovery, addressing the different obstacles demonstrated by the doctrine, as well as the legislative proposals that try to regulate the existing problems.
\end{abstract}

Keywords: judicial recovery; conflict of interests; deliberation crisis; critical theory. 


\section{INTRODUÇÃO}

O procedimento de recuperação judicial previsto na Lei 11.101/05 foi elaborado com o objetivo de substituir o processo de concordata até então vigente em nossa legislação, cuja eficácia e legitimidade para resolver os problemas da empresa em crise eram extremamente contestadas $^{1}$. Por outro lado, a atualização legislativa promovida pela referida lei de 2005 procurou favorecer a continuidade da atividade econômica, das relações de emprego e da tributação por parte do Estado, garantindo aos credores a prerrogativa de interferir na continuidade da empresa em dificuldade a partir do exercício do direito de deliberação sobre o plano de recuperação judicial, bem como do direito de fiscalizar os atos de reorganização das finanças da empresa em crise, fazendo com que o instituto seja cada vez mais utilizado pelos empresários e sociedades empresárias brasileiras, principalmente em substituição à falência ${ }^{2}$.

No que diz respeito às deliberações tomadas na Assembleia Geral de Credores (AGC), o regime legal da recuperação judicial estabelece, nos artigos 35 a 46 da Lei n. 11.101/05, entre outras coisas: o funcionamento da assembleia, sua composição, os critérios de votação e, principalmente, os requisitos essenciais para que um plano de recuperação judicial seja aprovado ou rejeitado. Em termos bastante resumidos, o artigo menciona que todas as classes de credores (previstos no art. 41 da Lei em questão) devem aprovar o plano de recuperação judicial para que o mesmo seja cumprido. Em cada classe, por sua vez, o plano deve ser aprovado por credores cujos votos representem mais da metade do valor total dos créditos, bem como pela maioria simples dos credores presentes. $\mathrm{O}$ artigo faz ainda a ressalva de que, no caso dos créditos trabalhistas, o critério para aprovação é apenas de maioria simples dos votantes, ou seja, independe de constituir a maior parte do valor dos créditos na referida classe. Para efeito da lei, só possui direito a voto na AGC os credores que tiveram as condições de pagamento originais alteradas no plano de recuperação judicial. Aprovado o plano em todas as classes de credores, cumpre-se o que fora decidido em assembleia. Rejeitado o plano por uma

1 Sobre um dos aspectos negativos do antigo regime de Concordata, Fábio Ulhoa Coelho relembra a existência de uma "indústria da concordara”, causada pela utilização abusiva do instituto por parte dos empresários devedores que enriqueciam ao final do processo, às custas do prejuízo de seus credores (COELHO, 2013). A existência deste e de outros problemas fazia com que o empresário credor deixasse de crer na cooperação para a manutenção da empresa em dificuldade como um mecanismo eficaz de regular os diversos interesses envolvidos. 2 Dados divulgados pelo Serasa Experian no jornal "Valor Econômico” indicaram, já nos primeiros anos de vigência da Lei 11.101/05, a crescente utilização da recuperação de empresas em substituição ao pedido de falência (TAIAR, 2016). 


\section{O CONFLITO DE INTERESSES NA RECUPERAÇÃO JUDICIAL: PROBLEMAS, PROPOSTAS LEGISLATIVAS E CONTRIBUIÇÕES CRÍTICAS}

das classes, desconsidera-se a possibilidade de recuperação judicial, e prossegue-se à falência do devedor.

Neste caso, assim como acontece em todas as situações de direito em que a decisão de um órgão representativo vincula os interesses em disputa, é que os problemas concretos se evidenciam. Um plano de recuperação aprovado nas diversas classes pode impor condições prejudiciais ao interesse de um determinado credor, o qual poderia preferir a cobrança do crédito em procedimento falimentar. Da mesma forma, um plano de recuperação rejeitado nos termos da lei pode estabelecer prejuízos aos interesses de um credor específico que desejasse a manutenção da empresa e de suas relações contratuais. Não é de se supor, portanto, que, em todos os casos, a manutenção da empresa é o objetivo final buscado por todos os envolvidos.

Neste contexto, assume significativa relevância a análise dos critérios legais de distribuição de poder de negociação e deliberativo entre os diversos agentes na recuperação judicial de empresas, o que abarca tanto a organização das classes de credores segundo a natureza do crédito, quanto a possibilidade de interferência do juiz da recuperação no resultado das votações. Diante de tais critérios, quais seriam as razões para considerar uma decisão tomada em assembleia de credores como legítima, considerando o conflito de interesses como uma condição inerente ao processo deliberativo? A obediência estrita ao regime normativo? A eficiência na distribuição de perdas e ganhos entre os participantes? O atendimento a uma concepção específica de democracia deliberativa? A escolha de uma ou mais razões entre as mencionadas expõe, certamente, pelo menos uma perspectiva sobre a qual é possível estudar o tema. Diante dessas circunstâncias, o presente artigo pretende abordar alguns dos problemas identificados pela doutrina com relação ao regime regulatório do conflito de interesses da recuperação judicial de empresas, as propostas legislativas relacionadas ao assunto, e algumas perspetivas teóricas de análise correspondentes, apontando as eventuais contribuições que uma abordagem crítico-estruturalista poderia oferecer.

\section{A PRODUÇÃO TEÓRICA NACIONAL}

Com relação à produção teórica relacionada ao tema, é mister destacar a contribuição do programa de pós-graduação em Direito da Universidade De São Paulo, em sua tradicional área de concentração relacionada ao Direito Empresarial. São inúmeras dissertações e teses 
publicamente disponibilizadas em seu repositório que abordam a recuperação de empresas e outros assuntos relacionados ao conflito de interesses em matéria empresarial, sob diferentes enfoques metodológicos e perspectivas teóricas. No presente artigo, foram escolhidos os trabalhos de Alvaro Mariano (2012), Fernando da Silva (2009) e Deborah Kirschbaum (2009). O primeiro, em razão do recorte adotado - abuso do direito de voto - o que e expõe uma das modalidades específicas do conflito de interesses na recuperação judicial de empresas. $O$ segundo, por sua vez, em razão da perspectiva interdisciplinar de análise, o que consideramos como inovador do ponto de vista da produção teórica nacional. O terceiro trabalho, por utilizar um abordagem teórica que consideramos mais adequada para o tratamento do conflito de interesses no Direito Empresarial.

Em segundo lugar, torna-se oportuno destacar que, no Brasil, a maioria dos estudos sobre o conflito de interesses na recuperação judicial de empresas se volta para os critérios relacionados à deliberação e aprovação do plano pelos credores na recuperação judicial, com especial atenção para a aplicação incorreta do art. 58 por parte da jurisprudência, de forma geral. Neste sentido, é oportuno apontar o que elucidativamente trata Eduardo Goulart Pimenta (2013), ao mencionar em seu artigo “Os limites jurisdicionais do direito de voto em recuperação de empresas" dois casos concretos (porém corriqueiros) em que os juízes questionados sobre a aprovação de plano rejeitado por uma das classes determinam a sua aprovação compulsória, sem mencionar se os requisitos do $\S 1^{\circ}$ do art. 58 estavam presentes e nem argumentar em que sentido haveria abuso do direito de voto por parte de um dos credores.

Ainda sobre o mesmo tema, não são poucos os autores de Direito Empresarial que criticam a utilização do instituto do “cram down” pela jurisprudência brasileira, alertando para a inobservância dos requisitos essenciais de sua verificação na doutrina americana. No mesmo panorama, aponta-se as considerações de Juliano Capelo de Souza (2012), assim como o mencionado artigo de Eduardo Goulart Pimenta (2010) e de Fabrício Oliveira e Keyla Melo (2013), os quais, além de abordarem a incorreta absorção do “cram down” pela lei brasileira, mencionam ainda o uso indiscriminado do instituto do “abuso de direito” em substituição aos critérios previstos no art. 58, § $1^{\circ}$, da Lei 11.101. Dentro dessa perspectiva, é importante ressaltar que embora os referidos autores concordem em relação aos problemas do “cram down” brasileiro, suas soluções são distintas em relação às soluções propostas para resolvê-los. Em resumo, os autores em questão divergem principalmente em relação à possibilidade ou não de o juiz ampliar de forma fundamentada as hipóteses de aprovação compulsória do plano de 


\section{O CONFLITO DE INTERESSES NA RECUPERAÇÃO JUDICIAL: PROBLEMAS, PROPOSTAS LEGISLATIVAS E CONTRIBUIÇÕES CRÍTICAS}

recuperação pelo juiz, o que embora se relacione com o presente objeto, não constitui a sua totalidade.

É necessário frisar que a divergência relacionada ao papel do juiz na aprovação compulsória do plano de recuperação judicial expõe uma importante relação entre a forma de organização da deliberação sobre a recuperação de empresas e a perspectiva teórico-política que embase a referida manifestação. Enquanto os posicionamentos contrários à ampliação de hipóteses da aprovação compulsória são influenciados pela ideia de autonomia das partes envolvidas e de reforço à segurança jurídica (pressupostos da ideia de justiça de influência do Estado Liberal), os adeptos da ampliação do papel do juiz defendem à submissão dos acordos e deliberações aos princípios e regras constitucionais, bem como à proteção de interesses de grupos minoritários (próprias de concepções de justiça Estado Social).

Na mencionada tese de doutorado de Alvaro Mariano (2012) são abordados algumas das possibilidades de aplicação do instituto do “abuso de direito” para o exercício do direito de voto na assembleia de credores, concluindo o autor que o voto pela “quebra” do empresário não é necessariamente contrária a função social da empresa, nem configuraria, por si, hipótese de abuso por parte do credor. O mesmo foi tratado por Amanda Espíndola (2010), sendo que, em ambos os casos, as análises procuram mapear o problema e propor soluções dentro de uma estrutura lógico-sistêmica, ou seja, a partir de uma perspectiva eminentemente positivista.

Fugindo ao estudo do problema a partir de uma perspectiva puramente sistêmica do Direito, Fernando Silva (2009) aborda o problema dos votos segundo a lógica da teoria dos jogos. Trata-se de uma importante contribuição para análise dos efeitos da organização normativa do problema, aplicando métodos da análise econômica do direito. O trabalho mapeia os incentivos legais para ocultação de informação, erro e voto abusivo por parte dos credores reunidos em assembleia, analisando a probabilidade de adoção de um ou determinado comportamento de acordo com a solução legal oferecida para os respectivos problemas.

Na tese de Deborah Kirschbaum (2009), orientada por Calixto Salomão Filho, a autora utiliza de uma base teórica fundada na governança corporativa como forma de analisar criticamente a regulação relacionada à composição de interesses no âmbito da legislação recuperatória, apontando como são formados os interesses de credores em dois momentos fundamentais: na formação dos agrupamentos de credores para votação e no estabelecimento dos quóruns deliberativos. 
Kirschbaum (2009) expõe que a percepção dos credores em relação aos limites de sua margem de negociação dos planos varia em razão da possibilidade de realização do ativo, considerando sua classe fixada em lei, o que incentivaria comportamentos tendentes a aprovar ou desaprovar um plano ignorando deliberadamente a atribuição de valor real à empresa. Na tese em questão, menciona-se a sub-representação de interesses contida na lei 11.101/05, que à época ainda não contava com a classe específica dos pequenos empresários. A autora faz questão de mencionar, contudo, que a mera ampliação do rol do art. 41 da Lei n. 11.101/05 não seria suficiente para solucionar os comportamentos voltados exclusivamente para o interesse pessoal dos credores, todavia, concluindo pela defesa de alterações legislativas relacionadas à formação de critérios materiais para trazer legitimidade tanto às propostas de recuperação quanto às deliberações dos credores:

Quanto à formação do plano de recuperação judicial e aos votos sobre ele proferidos, a tese defende que tanto as propostas como o exercício dos direitos de voto devem submeter-se a um juízo de legitimidade. A Lei contém regras expressas apenas quanto ao procedimento para aprovação do plano, as quais resumem-se à verificação de quorum, e não estabelece expressamente quais devam ser os parâmetros das propostas aos credores. Apesar disto, defende-se que o juízo de legitimidade em relação às propostas e à votação deva fundarse não apenas sobre as regras procedimentais contidas na Lei, mas sobre um critério material implícito ao ordenamento (KIRSCHBAUM, 2009, p. 203)

Conforme visto, os diversos trabalhos permitem identificar alguns dos problemas relacionados à regulação brasileira sobre os poderes de deliberação e de controle da recuperação judicial por parte dos credores e de outros agentes, servindo para mapear algumas das inconsistências constantes da Lei 11.101/05 relativas ao conflito de interesses na recuperação de empresas. Nestas circunstâncias, como tem reagido o poder legislativo diante das diversas críticas e sugestões realizadas pela pesquisa jurídica no Brasil? É o que se pretende analisar nas próximas linhas.

\section{AS PROPOSTAS LEGISLATIVAS PARA REGULAMENTAR O CONFLITO DE INTERESSES NA RECUPERAÇÃO DE EMPRESAS}


Conforme já abordado na revisão bibliográfica apresentada, são diversas as manifestações relacionadas ao conflito de interesses credores na realidade da recuperação judicial brasileira, sendo especialmente conhecida a possibilidade de acordos entre o devedor e alguns grupos de credores que, em razão da posse de maioria dos votos em suas respectivas classes (especificamente nas classes do inciso II e III do art. 58), conseguem a aprovação do plano, ainda que de forma contrária ao interesse de outros credores ${ }^{3}$. Sobre este tema específico, embora a própria Lei de Recuperação Judicial estabeleça alguns dispositivos que procuram impedir o tratamento diferenciado entre credores pertencentes a uma mesma classe (como o art. 58, §2 ${ }^{\circ}$, por exemplo), estabelecendo a concretização do princípio da par conditio creditorium, a referida proteção somente é invocada quando o plano de recuperação não é aprovado, e o juiz supera o veto assemblear, aprovando-o dentro de critérios quantitativos também estabelecidos em lei.

Os conflitos de interesses de credores de um procedimento de recuperação judicial não se materializam somente em relação à aprovação ou desaprovação do plano de recuperação de forma geral, todavia. No recente caso da recuperação judicial do grupo societário titular da marca da prestação de serviços de telecomunicação “Oi”, por exemplo, um dos principais grupos de credores é também titular de bônus de subscrição ou ações da companhia (REUTERS, 2017), o que poderia causar a aprovação de um plano cujas condições de pagamento das dívidas renegociadas sejam extremamente benéficas à recuperanda, podendo prejudicar credores de uma mesma classe creditícia que não possuíssem papéis da companhia. Não por acaso, o procedimento de recuperação do referido grupo tem se mostrado sem solução por alguns anos.

O caso da recuperação judicial da companhia aérea "VASP", por sua vez, talvez tenha sido uma dos mais emblemáticos em apontar os diversos conflitos de interesses surgidos na implantação do plano de recuperação da empresa, o que acabou por levar à decretação de falência da sociedade empresária após diversas reclamações judiciais de tratamento diferenciado dos credores (ALBUQUERQUE, 2016). Para além deste fato, e conforme demonstrado, a doutrina há muito vem apontando alguns dos problemas decorrentes da

3 Conforme já tratado na revisão bibliográfica relacionada ao assunto, a referida situação jurídica é comumente estudada sob a tutela do instituto do “cram down”, havendo divergências na doutrina quanto à sua recepção ou não no direito brasileiro. 
organização das deliberações conforme o regime adotado pela lei brasileira, seja em relação aos critérios de divisão entre classes e formação da maioria, ou no que diz respeito à imprevisão quanto à aplicação do instituto do abuso do direito de voto.

As ponderações realizadas pela doutrina e os problemas relacionados ao conflito de interesses de credores no contexto brasileiro não foram suficientes para uma alteração mais profunda do regime de deliberação nos mais de dez anos de vigência da lei, sendo oportuno ressaltar, contudo, as modificações introduzidas pela Lei Complementar n. 147 de 2014, que inseriu a "microempresa" (em sentido amplo) como uma mais uma classe de credores a votar em separado na assembleia de deliberação sobre o plano de recuperação judicial, estabelecendo o mesmo quorum e critério de aprovação dos créditos trabalhistas.

Por outro lado, organizaram-se no Brasil, nos últimos anos, algumas propostas legislativas de reforma no procedimento de deliberação sobre os planos de Recuperação Judicial. Dos projetos de lei que tratam diretamente do assunto, escolhemos abordar alguns que abordam especificamente questões relacionadas à resolução do conflito de interesses no momento de elaboração e deliberação sobre oplano de recuperação judicial. Neste contexto, destacam-se o projeto de lei n. 140/2011, de autoria do senador Alvaro Dias, e o projeto de lei n. 5.042/13 ${ }^{4}$, de autoria do deputado Carlos Bezerra. O primeiro propõe a regulação do rito de deliberação sobre o plano de recuperação judicial. Segundo consta da justificativa do referido projeto, os problemas relacionados à deliberação do plano de recuperação referem-se principalmente à inexistência de regramento claro quanto às oportunidades de manifestação por parte das classes de credores. Como solução, o autor do projeto sugere a inserção, na Lei 11.101/05, do artigo 37-A, o qual estabelece: primeiramente, uma regra que determina o mesmo tempo de manifestação para cada classe nas deliberações; necessidade de formalização das propostas de alteração; ordem de votação segundo a classe.

Com relação ao segundo projeto mencionado (5.042/13), são incorporadas em sua justificativa as algumas críticas relacionadas ao ativismo judicial, principalmente em relação às decisões que, em razão de não possuírem balizas legislativas adequadas, rejeitam o plano de recuperação até mesmo quando devidamente aprovado por todas as classes. A solução proposta pelo referido projeto, por sua vez, consiste em permitir o controle judicial diante de determinados limites traçados pela lei a ser criada. Mediante a inserção de parágrafo único ao

\footnotetext{
4 Este projeto não se encontra mais em tramitação, tendo sido arquivado pela Câmara dos Deputados. Todavia, em razão de abordar a questão do ativismo judicial e da necessidade de formação de balizas normativas para a intervenção do juiz no processo, considera-se oportuno mencioná-lo no presente trabalho.
} 


\section{O CONFLITO DE INTERESSES NA RECUPERAÇÃO JUDICIAL: PROBLEMAS, PROPOSTAS LEGISLATIVAS E CONTRIBUIÇÕES CRÍTICAS}

art. 35 da Lei de Falências e Recuperação, o autor do projeto estabelece que a aprovação do plano pela Assembleia não pode ferir os princípios gerais de direito, as normas públicas e os princípios constitucionais, sob pena de ser rejeitado pelo juiz.

Em outro sentido, destaca-se a iniciativa contida no projeto de lei 331/2010, de autoria da senadora Ideli Salvati. O projeto tem como objetivo autorizar o executivo a criar o "Comitê Gestor de certificação de processos de recuperação judicial”, cuja composição seria preenchida por membros do Conselho Nacional de Justiça; dos Ministérios da Justiça e do Desenvolvimento, Indústria e Comércio; e de especialistas ligados ao projeto "Recupera Brasil”, uma associação sem fins lucrativos. A ideia é permitir que o referido comitê contrate assessoria técnica especializada para a realização de diversas consultorias em tribunais e outras entidades interessadas na Recuperação Judicial, em razão das dificuldades encontradas na aplicação do instituto em comarcas sem varas especializadas, bem como por motivo da ausência de orientação dos próprios credores em relação às possibilidades de recuperação.

A movimentação legislativa em torno do tema expõe a necessidade de rediscussão do sistema de deliberação do regime de recuperação de empresas brasileiro, ao mesmo tempo em que fornece alguns indícios das influências teóricas ou ideológicas presentes nas propostas abordadas. Enquanto algumas propostas procuram apenas regular o tempo ou a igualdade de condições de manifestação nas deliberações, outras manifestam a ideia de submissão da vontade dos credores ao sistema normativo, relativizando o caráter negocial das decisões. Há também, propostas que apontam para uma perspectiva da participação de agentes sociais não diretamente envolvidos na relação jurídica creditícia, o que pode indicar tanto uma preocupação com as “externalidades” da deliberação, bem como uma ideia de conflito de interesses não necessariamente individualistas.

\subsection{A PROPOSTA DO NOVO CÓDIGO COMERCIAL}

O Projeto de Novo Código Comercial (PL1572/2011), de iniciativa do deputado Vicente Candido, tem sido objeto de diferentes manifestações da doutrina de direito empresarial a 
respeito de sua necessidade, consistência e precisão teórica ${ }^{5}$. Influenciado pela ideia de que especialização da legislação de Direito Comercial em relação ao Direito Civil trará maior segurança jurídica na forma de uma sistematização concentrada do conteúdo legislativo empresarial, o referido projeto de lei contém dispositivos que impactam não somente a parte do Direito da Empresa previsto no atual Código Civil, mas também nas legislações esparsas.

No referido documento legislativo, para além de uma significativa reforma regulatória do Direito Empresarial, é proposta, no que pertine à recuperação de empresas, as seguintes propostas normativas: inserção do requisito da "boa fé” dos participantes de deliberações em assembleia e reforço do caráter negocial das deliberações (art. 602); aplicação das normas de relativas à assembleia geral de acionistas da sociedade anônima (art. 602, p. único); a insuficiência da rejeição do plano de recuperação como fundamento para conversão da recuperação em falência (art. 603).

Diante das propostas de alteração da Lei de Recuperação Judicial e Falência produzidas pelo projeto de Novo Código Comercial, percebe-se que importantes questões debatidas pela doutrina foram deixadas de fora, quais sejam: a formação de critérios materiais para o estabelecimento de um verdadeiro “cram down”, no Brasil; o controle do abuso de direito exercido por meio de voto contrário a interesses juridicamente protegidos; normas incentivadoras de comportamento cooperativo entre credores e elaborador do plano. Não obstante, as alterações propostas pelo referido projeto devem ser devidamente analisadas de acordo com a perspectiva teórica que fundamente o presente artigo.

\section{A TEORIA CRITICO-ESTRUTURALISTA DO DIREITO EMPRESARIAL E SUAS POSSÍVEIS CONTRIBUIÇÕES PARA O CONFLITO DE INTERESSES NA RECUPERAÇÃO DE EMPRESAS}

Entre as diversas perspectivas teóricas que podem embasar uma pesquisa jurídica, a perspectiva positivista é, possivelmente, uma das possibilidades mais recorrentes nas faculdades brasileiras. Diante de uma visão racional-positivista, a interpretação a respeito de um problema ou fato jurídico ocorre dentro dos limites traçados pela própria noção de sistema

5 Desde a sua tramitação, diversos professores, pesquisadores e profissionais da área se manifestaram publicamente a respeito do projeto em questão. Em carta endereçada ao deputado relator do projeto de lei e divulgada pelo site Conjur, os professores Newton de Lucca, Calixto Salomão Filho e Paula Forgioni (2016) da Universidade de São Paulo questionam a conveniência do momento de propositura da referida proposta legislativa, bem como apontam alguns pontos espinhosos da proposta. 


\section{O CONFLITO DE INTERESSES NA RECUPERAÇÃO JUDICIAL: PROBLEMAS, PROPOSTAS LEGISLATIVAS E CONTRIBUIÇÕES CRÍTICAS}

jurídico, ocasião em que importa muito mais ao jurista formar logicamente as ligações entre os elementos normativos de modo a obter um conjunto pré-definido de valores, os quais, por decorrerem de uma abstração - a norma - assumiriam a natureza de "dados” ou "fatos sociais”, o que poderia conferir-lhes certo grau de "neutralidade”.

Na verdade, conforme nos alerta Thomas Bustamante (2005) há certa confusão na doutrina a respeito dos termos “positivismo" e “formalismo jurídico”, configurando o primeiro o conjunto de teorias que militam em torno da separação conceitual entre direito e moral, enquanto o segundo se volta mais para a defesa de uma atitude do intérprete jurídico conforme os parâmetros normativos do sistema jurídico ao qual pertencem. Ambos, contudo, enxergam no direito um sistema capaz de se formar por si mesmo, e que possui uma lógica própria, da qual se alimenta sem a necessária contribuição de outras áreas do conhecimento.

Não por acaso, diversas teorias pós ou anti-positivistas buscaram incorporar determinados aspectos destas outras áreas do conhecimento para analisar os fenômenos jurídicos, assumindo perspectivas e métodos próprios de outros ramos do conhecimento, como a Filosofia Moral, a Sociologia e a Economia, por exemplo. No Direito Público brasileiro, a influência de autores como Ronald Dworkin (2007) e de sua Filosofia Moral é sentida pela proposta de redefinição da atuação do juiz nos casos difíceis, o que significa uma tentativa de superar as barreiras existentes entre o que diz o direito e o que realmente deveria ser dito.

No âmbito do Direito Empresarial, por sua vez, é comum verificar a absorção de instrumentos típicos da Economia para a investigação sobre seus objetos, que se manifestam sobretudo a partir da utilização da Análise Econômica do Direito. Pensada a partir da iniciativa de economistas e juristas vinculados à Escola de Chicago, a AED propõe que o Direito deve resolver seus casos a partir da noção de que o destinatário de seus comandos é, além de homem, um "homo economicus”, ou seja, que tende à maximizar o seu próprio bem estar nas relações com os demais, e que as medidas que pretendam influenciar em seu comportamento são tanto mais eficazes quanto mais atentas a este fator. Desta forma, estabelecem soluções para casos jurídicos pensando não apenas com base no que consideram “justo” (embora o paradigma moral liberal e utilitarista esteja sempre presente), mas principalmente na adequação das medidas impostas aos resultados comportamentais esperados. 
A teoria crítico-estruturalista ${ }^{6}$, como as demais teorias apresentadas, parte da crítica à visão positivista do problema jurídico, o qual, no presente caso, é estabelecido a partir do processo de deliberação de credores na recuperação judicial de empresas. Preocupa-se, portanto, em não permanecer engessado à realidade normativa, tendo em vista a dinamicidade das próprias relações sociais, principalmente das relações de produção e circulação de mercadorias e serviços. Preocupa-se, também, em evitar a construção de soluções “compensatórias”, caracterizadas por regras que redistribuem algumas das distorções de poderes entre os agentes sociais conferindo-lhes privilégios em outras searas (a exemplo do Direito do Trabalho e do Consumidor). Por outro lado, a teoria crítica do Direito não se resume a "chavões de homens de negócios”, nos termos de Calixto Salomão FIlho (2015, p. 7), desconsiderando os efeitos físicos e sociais relacionados à cultura do hiper-consumo, da hiperprodutividade e da hiperexploração dos recursos naturais.

Dessa forma, a teoria crítico-estruturalista elaborada por Calixto Salomão não é, portanto, uma exata tradução das perspectivas teóricas que emprestam significado ao seu nome, embora contenha importantes elementos de ambas na formulação de uma metodologia própria de investigação sobre o Direito Empresarial ${ }^{7}$. Na perspectiva crítico-estruturalista do Direito Comercial, o caráter critico se refere ao papel do pesquisador do direito em não apenas identificar as estruturas sociais e o modo como os homens organizam a vida em sociedade por meio de normas jurídicas, mas, preocupa-se, sobretudo, com a proposição de mecanismos de reorganização do sistema jurídico e social. Dessa forma, a crítica ocorre paralelamente ao movimento de construção de propostas viáveis de alteração do sistema econômico e jurídico. Sobre a preocupação com a viabilidade das propostas, ressalta-se a necessidade de fuga às soluções baseadas em uma exclusiva teoria do valor ou da moral, que geralmente atribuem à

\footnotetext{
6 É possível que o que Calixto Salomão tenha desenvolvido não seja propriamente uma teoria, na medida em que não corresponde a uma formulação geral explicativa sobre determinado fenômeno. No sentido adotado pelo autor, teoria parece estar relacionada a adoção de determinados procedimentos teórico-metodológicos que determinam o sentido da investigação dos problemas relacionados ao Direito Empresarial.

7 Sobre a teoria crítica, em geral, entende-se a abordagem teórica das ciências sociais adotada por autores da Escola de Frankfurt do pós-guerra, no século XX, cujo membro tradicionalmente apontado como o precursor deste movimento é o filósofo, sociólogo e psicólogo social Max Horkheimer. A Escola de Frankfurt é considerada como uma escola de pensamento, ao mesmo tempo em que se caracterizava como um espaço de trabalho compartilhado por diferentes pensadores. Como escola de pensamento, era marcada por um viés marxista, porém inovador em relação aos intérpretes mais literais de Marx, na media em que incorporava contribuições de outras áreas do conhecimento - como a psicologia social e a antropologia social - não relevantes ao tempo de Marx e Engels, e que tentavam fugir ao determinismo histórico relacionado à luta de classes conforme previsto pelo filósofo e economista alemão. O estruturalismo, por sua vez, que tem sua origem no estudo da linguística como formação de uma estrutura social compartilhada, assume na psicologia, na antropologia e em outras áreas do saber especial predominância ao estudar as relações a partir da identificação de tais estruturas.
} 


\section{O CONFLITO DE INTERESSES NA RECUPERAÇÃO JUDICIAL: PROBLEMAS, PROPOSTAS LEGISLATIVAS E CONTRIBUIÇÕES CRÍTICAS}

intenção do agente o caráter definitivo de existência ou inexistência de justiça em uma conduta. No presente artigo, a referida postura teórica servirá de guia para análise das propostas legislativas tendentes a alterar o procedimento de recuperação judicial, especialmente no que diz respeito à regulamentação do conflito de interesses.

\section{ANALISANDO CRITICAMENTE AS PROPOSTAS LEGISLATIVAS EXISTENTES A RESPEITO DO CONFLITO DE INTERESSES NA RECUPERAÇÃO JUDICIAL}

As diferentes perspectivas ideológicas contidas nas propostas legislativas apresentadas correspondem a, consequentemente, distintas perspectivas teóricas de análise do tema, as quais merecem ser devidamente identificadas. Como primeira delas, podemos citar o Utilitarismo ou a Análise Econômica do Direito, contidos na proposta dos projetos de lei n. 140 e 5042, ambos influenciados pelos pressupostos fundamentais de que a maximização do bem-estar coletivo é o principal objetivo a ser perseguido pelas instituições e que este objetivo seria garantido exclusivamente pelo incremento da autonomia privada e da livre negociação no mercado, bem como pela desburocratização ou desregulamentação.

Sobre este viés, entende-se que o mesmo forneceria importantes diretrizes de organização da regulação sobre a tomada de decisões por uma assembleia de credores e suas consequências. Todavia, consideramos que o incentivo às trocas livres e o reforço da autonomia das decisões contratuais não são suficientes para fornecer uma interpretação sobre a regulação que represente os contornos atuais os assumidos pelo que entendemos por Estado Democrático de Direito. Para além de garantir a autonomia das partes em se vincular a contratos e se responsabilizar por sua vontade, o que sugerem mudanças procedimentais na legislação, entendemos que esta autonomia somente pode surgir a partir de mecanismos materiais de equilíbrio nas negociações entre os agentes, o que definitivamente não ocorre na legislação brasileira a respeito das deliberações na recuperação judicial.

No contexto da deliberação de credores da recuperação de empresas, é preciso pensar em instrumentos de correção aos resultados de um arranjo violador de direitos, consequência das falhas de equilíbrio no ponto de partida. Isso não quer dizer que se defenda a interferência estatal personificada na vontade de um de seus agentes públicos. Em resumo, é preciso apontar caminhos regulatórios capazes de permitir o controle judicial das decisões com base em 
critérios materiais seguros e previsíveis para os agentes envolvidos, evitando intervenções judiciais baseadas em preconcepções valorativas impostas de cima para baixo. O trabalho de Kirschbaum (2009), conforme verificado na revisão bibliográfica, apontou a existência de, pelo menos, um critério material implícito no sistema brasileiro regulatório da empresa em crise para o exercício deste controle, qual seja, a certeza de que as condições de recebimento do crédito na recuperação devem ser iguais ou melhores do que na hipótese de uma liquidação forçada da empresa.

A proposta de reforma da senadora Ideli Salvati, ao criar uma estrutura representativa de diversos setores da sociedade no âmbito da recuperação de empresas, aborda um problema também identificado por Kirschbaum (2009), a sub-representação de interesses no esquema geral da Lei n. 11.101/05. Neste sentido, consideramos a iniciativa inovadora do ponto de vista da instalação de uma governança, considerando que o controle social do procedimento por diferentes agentes especializados no assunto garantiria um alinhamento dos objetivos da lei recuperatória. Todavia, a criação de órgãos públicos é sempre um problema de ordem pragmática, principalmente no que tange à disponibilização de recursos estatais para a sua realização.

No que diz respeito às perspectivas voltadas para a ampliação do poder do juiz na condução do ambiente de negociação e de votação do plano de recuperação judicial, não se verificou qualquer inovação a respeito da formulação de critérios materiais para controle das deliberações no âmbito da recuperação. A proposta encaminhada neste sentido, conforme visto, limitou-se a submeter o acordo recuperatório ao controle judicial com base nos princípios gerais de direito e normas constitucionais, o que entendemos como uma medida desnecessária do ponto de vista do funcionamento do sistema jurídico.

\section{CONCLUSÃO}

O presente trabalho pretendeu abordar alguns dos problemas que envolvem a deliberação e o conflito de interesses no âmbito da recuperação de empresas, apresentando as contribuições teóricas que tangenciavam este tema como objeto de estudo, bem como o acompanhamento das tendências legislativas que se propuseram a oferecer soluções. Na perspectiva adotada neste artigo, considerou-se que a Teoria Crítico-Estruturalista do Direito 


\section{O CONFLITO DE INTERESSES NA RECUPERAÇÃO JUDICIAL: PROBLEMAS, PROPOSTAS LEGISLATIVAS E CONTRIBUIÇÕES CRÍTICAS}

Empresarial seria uma forma adequada de investigação do problema, em razão de trabalhar com interesses concretos dos agentes em vez de formulações abstratas relativas a concepções individuais de justiça.

No que diz respeito à intenção dos agentes envolvidos na recuperação de empresas, conclui-se que o interesse objetivamente considerado dos agentes envolvidos forneceria elementos regulatórios muito mais concretos da conduta e das possibilidades de equilibrar as relações sociais, conforme verificado nas contribuições inovadoras propostas pela doutrina ao longo dos últimos anos. Conforme foi possível perceber, todavia, as propostas regulatórias relacionadas ao assunto não escolheram o referido caminho, optando por construir tímidas contribuições legislativas relacionadas à organização das assembleias e ao poder de controle das deliberações por parte do juiz da recuperação, em geral restritas a aspectos procedimentais ou de criação de órgãos públicos.

\section{REFERENCIAS}

ALBUQUERQUE, Flavia. Justiça determina pagamento de direitos a ex- funcionários da Vasp. Agência Brasil, 2016. Disponível em: <http://agenciabrasil.ebc.com.br/geral/noticia/201602/justica-determina-pagamento-de-direitos-ex-funcionarios-da-vasp>

BOBBIO, Norberto. Da estrutura à função: novos estudos de teoria do direito. Manole, 2007.

BRASIL, Código Civil. Lei $\mathrm{n}^{\circ}$ 10.406, de 10 de janeiro de 2002. Disponível em: http://www.planalto.gov.br/ccivil_03/leis/2002/110406.htm

BRASIL. Lei No. 11.101, de 09 de fevereiro de 2005. Regula a recuperação judicial, a extrajudicial e a falência do empresário e da sociedade empresária. Disponível em: <http://www.planalto.gov.br/ccivil_03/_Ato2004-2006/2005/Lei/L11101.htm>

BRASIL, Projeto de Lei do Senado n. 140, de 2011. Acrescenta artigo à Lei no 11.101, de 9 de fevereiro de 2005, para dispor sobre o rito da assembleia geral de credores que delibera sobre o plano de recuperação judicial. Disponível em: <https://legis.senado.leg.br/sdleggetter/documento?dm=618141\&disposition=inline> 
BRASIL, Projeto de Lei do Senado n. 331, de 2010. Autoriza o Poder Executivo Federal a criar o Comitê Gestor de certificação de processos de recuperação judicial, na forma da Lei n.

11.101/05, de 09 de fevereiro de 2005. Disponível em: <https://legis.senado.leg.br/sdleggetter/documento?dm=619961\&disposition=inline>

BRASIL, Projeto de Lei n. 1572, de 2011. Institui o Código Comercial. Disponível em: $<$ http://www.camara.gov.br/proposicoesWeb/prop_mostrarintegra;jsessionid=50BA041F6857 394CBC359EA0E692DBD2.proposicoesWebExterno2? codteor $=888462 \&$ filename $=$ Tramitac ao-PL+1572/2011>

BRASIL, Projeto de Lei n. 5.042 de 2013. Acrescenta parágrafo único ao art. 35 da Lei no 11.101, de 9 de fevereiro de 2005, que "Regula a recuperação judicial, a extrajudicial e a falência do empresário e da sociedade empresária”, com o objetivo de disciplinar a aprovação do plano de recuperação judicial pela assembleia de credores.

BUSTAMANTE, Thomas da Rosa. Argumentação Contra Legem: a teoria do discurso e a justificação jurídica nos casos mais difíceis. São Paulo: Renovar. 2005.

COASE, Ronald H. The nature of the firm. economica, v. 4, n. 16, p. 386-405, 1937.

COELHO, Fábio Ulhôa. Comentários à Lei de Falências e de recuperação de empresas. São Paulo: Saraiva, 2013.

DE LUCCA, Newton, et al. Carta ao deputado Paes Landim. Conjur, 2016. Disponível em: $<$ https://www.conjur.com.br/dl/codigo-comercial-nao-ataca-problemas.pdf>

DE SOUZA, Juliano Capello. “Cram Down”: Uma comparação entre o US Code e a Lei 11.101/05. Revista Fonte Universitária, Juatuba- MG, v.3, n.4, jan./jul. 2012

DE SOUZA NETO, Cláudio Pereira. Teoria constitucional e democracia deliberativa: um estudo sobre o papel do direito na garantia das condições para a cooperação na deliberação democrática. Renovar, 2006.

CORRÊA-LIMA, Osmar Brina; LIMA, Sérgio Mourão Corrêa (Coord.). Comentários à nova lei de falência e recuperação de empresas. Rio de Janeiro: Forense, 2009.

DWORKIN, Ronald. A democracia possible: princípios para um nuevo debate político. Tradução Ernest Weikert Garcia. Barcelona: Paidós Ibérica S.A, 2007. 
ESPINDOLA, AMANDA VILARINO. Do abuso de direito de voto em assembléia geral de credores no processo de recuperação judicial. 2010. Tese de Doutorado. Dissertação de Mestrado. Nova Lima: Faculdade de Direito Milton Campos.

GONÇALVES, Oksandro Osdival; DE SIQUEIRA, Felipe de Poli. A aprovação do plano de recuperação de empresas: uma questão de escolha à luz da teoria dos jogos. Revista da AJURIS, v. 41, n. 133, 2014.

KIRSCHBAUM, Deborah. A recuperação judicial no Brasil: governança, financiamento extraconcursal e votação do plano. 2009. Tese de Doutorado. Universidade de São Paulo.

LOBO, Jorge. Comentários à lei de recuperação de empresas e falências. Paulo F. C. Salles de Toledo e Carlos Henrique Abrão (coords.). São Paulo: Saraiva, 2005.

LOBATO, Moacyr. Falência e recuperação. Editora del Rey, 2007.

MARIANO, Alvaro Augusto Camilo. Abuso de voto na recuperação judicial. 2012. Tese de Doutorado. Universidade de São Paulo.

MELLO, K. A. ; OLIVEIRA, F. S. . Problemas na aplicação do cram down brasileiro: uma proposta alinhada à teoria de Richard Posner. In: Márcia Carla Pereira Ribeiro; Sandro Mansur Gibran; Antônio Carlos Diniz Murta. (Org.). Direito Empresarial. 2ed.Florianópolis: FUNJAB, 2013, v. 1, p. 272-296.

MENEZES, Maurício Moreira Mendonça de. O poder de controle nas companhias em recuperação judicial. Rio de Janeiro: Editora Forense, 2012.

PIMENTA, E. G. . Os limites jurisdicionais do direito de voto em recuperação de empresas. Novos Estudos Jurídicos (Online), v. 18, p. 151-161, 2013.

POPPER, Karl R. A lógica da pesquisa científica. Editora Cultrix, 2004

REUTERS. Credores da Oi querem que alguns investidores sejam barrados em assembleia. UOL, 2017.2 Disponível em: $<$ https://economia.uol.com.br/noticias/reuters/2017/09/20/credores-da-oi-querem-que-algunsinvestidores-sejam-barrados-em-assembleia.htm?cmpid=copiaecola> 
SALOMÃO FILHO, Calixto. O novo direito societário. 3. ed São Paulo : Malheiros, 2006.

SALOMÃO FILHO, Calixto. Teoria crítico-estruturalista do direito comercial. 1 ed. São Paulo: Marcial Pons, 2015.

SILVA, Fernando César Nimer Moreira da. Incentivos a decisao de recuperacao da empresa em crise: analise a luz da teoria dos jogos. 2009. Tese de Doutorado. Universidade de São Paulo.

SOUZA, Francisco Satiro de; PITOMBO, Antonio Sérgio A. Comentários à Lei de Recuperação de Empresas e Falência: Lei 11.101/2005. São Paulo: Editora Revista dos Tribunais, 2007.

STAJN, Rachel. Comentários à Lei de Recuperação de Empresas e Falência. Paulo F. C. Salles de Toledo e Carlos Henrique Abrão (coords.). São Paulo: Saraiva, 2005.

TAIAR, Estêvão. Pedidos de recuperação judicial aumentam 30\% em janeiro, aponta Serasa. Valor Econômico, 2016. Disponível em: <http://www.valor.com.br/brasil/4422566/pedidosde-recuperacao-judicial-aumentam-30-em-janeiro-aponta-serasa $>$

WEBER, Max. Economia e sociedade: fundamentos da sociologia compreensiva. v. 1. Brasília: UnB, 1999. 